\title{
A New Methodology to Assess Indirect Losses in Bridges Subjected to Multiple Hazards
}

\author{
Davide Forcellini ${ }^{\mathrm{a}^{*}}$ \\ ${ }^{a}$ Università di San Marino, San Marino
}

\begin{abstract}
Decision making approaches to manage bridge recovering after the impact of multiple hazards are increasing all over the world. In particular, bridges can be considered critical links in highway networks because of their vulnerability and their resilience can be assessed on the basis of evaluation of direct and indirect losses. This paper aims at proposing a new methodology to assess indirect losses for bridges subjected to multiple hazards. The method applied to calculate direct costs is the credited Performance Based Earthquake Engineering (PBEE) methodology by the Pacific Earthquake Engineering Research (PEER) center. Therefore, the main objective of the study consists in the assessment of indirect losses that are generally neglected elsewhere. In particular, the paper proposes to calculate indirect losses from direct costs and to divide them into connectivity losses and prolongation of time. The presented formulation has been applied to a real case study aimed at strengthening a benchmark bridge with several isolated configurations. The results show that the application of the proposed methodology allows to evaluate possible solutions to strengthen the original configuration.
\end{abstract}

\section{Keywords:}

Type Your Keywords Here;

Separated By Semicolons;

Response Site Analysis;

Opensees;

Numerical Simulations;

Eurocode 8.

\section{Article History:}

Received: 02 October 2018

Accepted: 07 December 2018

\section{1- Introduction}

Bridges are lifeline structures acting as important links in surface transportation network. Their collapse and damage due to multiple hazards affects social and civil functionality Forcellini (2017) [1]. In particular, multiple hazards (such as ground movements, debris flow, floods and man-hand events) have been identified from several contributions (Gelh and D'Ayala (2016), Andric and Lu (2016), Quang et al. (2015), Alipour et al. (2015) [2-5]). Such impacts affect the functionality of bridges and thus the societies and the businesses that rely heavily on them. In addition to loss of life and the physical losses, bridge damages and collapse may cause significant socio-economic losses and impacts, as shown recently in Pitilakis et al (2016), [6]. For example, recent studies on US bridges revealed that 53\% of the failures between 1989 and 2000 were due to hydraulic causes Wardhana and Hadipriono (2003) [7], in particular scour, stream pressure caused by floods, and debris accumulation. It can be estimated that in Europe and USA there are approximately two million highway and railway bridges. Among them, almost $10 \%$ are characterised as structurally deficient and $14 \%$ as functionally obsolete FHWA (2015) [8] even if almost half a trillion trips across them are taken on a daily basis. Since the world economies and user safety heavily rely upon these bridges, the assessment of repairing and strengthening procedures is becoming a fundamental issue. In such background, the resilience-based design and assessment of bridges is an urgent issue of paramount importance in order to efficiently allocate resources toward resilient transportation networks.

In this regard, resilience is the ability of a system (specifically a bridge) to reduce the consequences of an event by limiting damage and loss of functionality, Bruneau et al. (2003) [9]. In bridge arena, it is important to take into consideration both the technical and economic aspects (related to the functionality) and the organizational and social aspects (related to the entire community). In this regard, methodologies need to be studied in order to define resilient

\footnotetext{
* CONTACT: Davforc@omniway.sm

DOI: http://dx.doi.org/10.28991/esj-2018-01159

(C) This is an open access article under the CC-BY license (https://creativecommons.org/licenses/by/4.0/).
} 
bridges and assessing several key factors such as damage probabilities, consequences and recovery costs. In this context, fragility and restoration models for bridges subjected to a range of hazards are essential tools for accurate quantification of their resilience Zhang and Wang (2016) and Cimellaro (2016) [10, 11]. In particular, fragility models allow the probabilistic assessment of levels of damage, while restoration models quantify the recovery times and procedures. These methodologies have attracted increased attention recently with the aim to facilitate and enhance pre-hazard and post-hazard event mitigation and emergency response strategies of transportation systems and entire communities Gidaris et al (2017) [12].

In addition, modern communities can register serious damages in cases of natural or manmade disasters, whose impacts have been analysed in literature (Tierney K.J. et al. (1995), Wasileski et al (2011), Webb et al (2002), Chang et al. (2002), [13-17]). In particular, integrity of transportation assets is fundamental for communities and societal resilience that heavily relies on infrastructure. The analyses of post-disaster situations have been shown in Chang and Shinozuka (2004) and Renschler (2010), [18, 19]. Recently quantitative risk analyses (QRA) have been proposed in order to protect critical infrastructure assets (such as bridges) subjected to natural hazards (Cabinet Office UK 2010; Council Directive 2008/114/EC; EC SWD 2013/137). In this regard, QRA quantifies scientifically the risk as to provide the basis for the prioritization of management and mitigation actions. In particular, economic impacts on bridges should be defined in terms of structural damage and costs associated with traffic flow. These losses should include both direct and indirect costs (Brookshire et al (1997), Forcellini (2016), [20, 21]). As shown in Adey et al (2004) [22], direct costs are those incurred by the infrastructure owner, such as material and labor costs due to undertake an action (i.e. deck replacement and rehabilitation). Indirect cost are those incurred by users such as travel time and vehicle operating costs. In particular, indirect costs depend not only on structures but also on network conditions. In addition, indirect losses to the surrounding region include time delays that induce interruption of goods and services. This complex dimension of indirect costs, makes difficult to take into account their role in decision making procedures.

This paper aims to develop a new methodology that can allow decision making procedures aimed at assessing the resilience of bridge configurations by taking into account indirect losses. The principal novelty of such paper is that it proposes to assess indirect losses from direct costs by introducing some hypothesis and parameters that can be calibrated with statistical data from existing case studies. The paper is organized into 6 sections. Indirect losses and the case study in are defined in section 2 and 3 respectively. Section 4 specifies the hypothesis under which indirect losses are calculated. Section 5 shows the results.

\section{2- Indirect Losses}

Losses resulted from natural hazards can be divided into direct losses (such as repair of infrastructure, replacement of damaged contents and components) and indirect losses (business disruptions, relocations expenses, supply chain interruption), as shown in Brookshire et al (1997) [20]. In particular, Adey et al (2004) [22] show that indirect losses of an infrastructure network can be divided into two categories: those associated with temporal prolongation of time and those associated with loss of connectivity. In general, since indirect losses affect the communities that is served by the infrastructure, it is fundamental to take into account the source of the damage. When the failure is due to natural events such as earthquakes and floods, it is realistic to consider the possibility that more than a single bridge can be affected by the loss of functionality. Therefore, a realistic decision making assessment should take into account simultaneous failures. Consequently, Adey et al (2004) [22] shows that another typology of indirect losses should be taken into account in order to consider the probability of simultaneous failed bridges. Another important parameter in indirect cost analyses is the infrastructure redundancy, defined as the chance of connection loss. Redundancy can highly affect the economic losses occurring when travel on that particular infrastructure is not possible. In particular, Adey et al (2004) [22] shows that the total indirect losses incurred for an infrastructure network are the sum of additional indirect costs multiplied for the probability that the infrastructure is in a specific single damage state.

The aim of this paper is to propose a new methodology that can take into account indirect costs for bridge decision making assessment. In particular, the application of such theoretical approach for a single bridge is here considered. Due to the extreme complex dimensions of the problem, several simplifications has been made in order to specify the definition of indirect losses. First of all, the typology of the failures is fundamental. When a single bridge fails and it may be assumed that all other bridges are operational, then the probability of multiple failures can be considered negligible. This is realistic for those events as collisions or terrorist attacks that can be considered isolated events. For earthquakes, such circumstances can be considered still realistic. However, when other events, for example floods or hurricane are considered, probability of multiple failures cannot be considered negligible. This paper considers the assessment of bridges during earthquakes only. Therefore, the contemporary failure of bridges is not considered. Another important hypothesis is the proposal to consider indirect costs dependent on repair time due to recovery procedures. This hypothesis helps to reduce the uncertainties around the indirect losses definition and it allows to use the existing methodologies that assess the direct losses. In particular, following Forcellini (2017) and Lu et al. (2011), [1], [23], indirect losses can be calculated by considering the Performance Based Earthquake Engineering (PBEE) methodology, by the Pacific Earthquake Engineering Research (PEER) center. In particular, PEEB methodology, Mackie et al (2010), 
[24], aims at assessing structural performances in terms of probability of exceeding threshold values of socio-economic decision variables (DVs) in seismic hazard environment. Repair time is estimated by applying the concept of fragility curves, as shown for example in Billah and Alam (2015) and Karamlou and Bocchini (2015), [25, 26]. In this regard, fragility curves define the probability of exceed some limit states of the bridge by taking into account specific intensity measure (Im) variables, such as PGA. This is fundamental in order to relate the indirect losses to the probability of occurrence of particular limit states of the bridge that are defined by structural conditions at the relative losses in terms of repair costs and repair time. PBEE methodology calculates the total repair cost ratio (RCR: defined as the ratio between the repair costs and the cost of replacement) and the repair time (RT) express in crew working days. These two variables represent the two main parameters that condense all the multi-dimensional results for decision making procedures. In particular, this paper considers the two sources of indirect costs (loss of connectivity and temporal prolongation of travel) as functions of repair time.

\section{3- Case Study}

This section analyses a case study with the aim to assess several repair methods among bridge alternative configurations. In particular, the original bridge (named MODEL 1) is intended to be representative of prevalent ordinary construction types for California highway. In this regards, some standard dimensions are taken into consideration. The bridge is a $90 \mathrm{~m}$ long, 2-span structure, supported on one circular column (1.22 m diameter) $12 \mathrm{~m} \mathrm{long,} 6.70 \mathrm{~m}$ above grade (Figure 1). The deck is $11.90 \mathrm{~m}$ wide and $1.80 \mathrm{~m}$ deep. Each abutment is $25 \mathrm{~m}$ long with $30000 \mathrm{kN}$ as total weight. Connections between the abutments and the deck consists of roller links with no resistance. The column has fixed connections with the deck. Then, three strengthening configurations have been studied and compared with the original one. In particular, isolation devices are used in place of conventional bridge bearings in order to protect the substructure by restricting the transmission of seismic accelerations and dissipating energy. The three isolated configurations are defined as:

Model 2: deck - abutments connections realized with elastomeric bearings while column - deck connection is still fixed;

Model 3: column - deck connection consisting of elastomeric bearings at the top of the column, while deck and abutments are still free to move (no resistance);

Model 4: a double-isolated configuration with elastomeric bearings in correspondence of the each abutments and on the top of the column.

Following literature contributions (such as Kelly (1997), Forcellini and Kelly (2014) and Forcellini (2017) [27], [28], [1]), isolation devices are modelled with linear springs (whose characteristics are described in Table 1). The results in terms of RCR and RT (Figure 3 and 4) show that the various isolated models reduce the damage for several intensities of earthquakes. Results in terms of RT (Figure 4) shows that there are particular levels of PGA where it is possible to see an increase of RT.

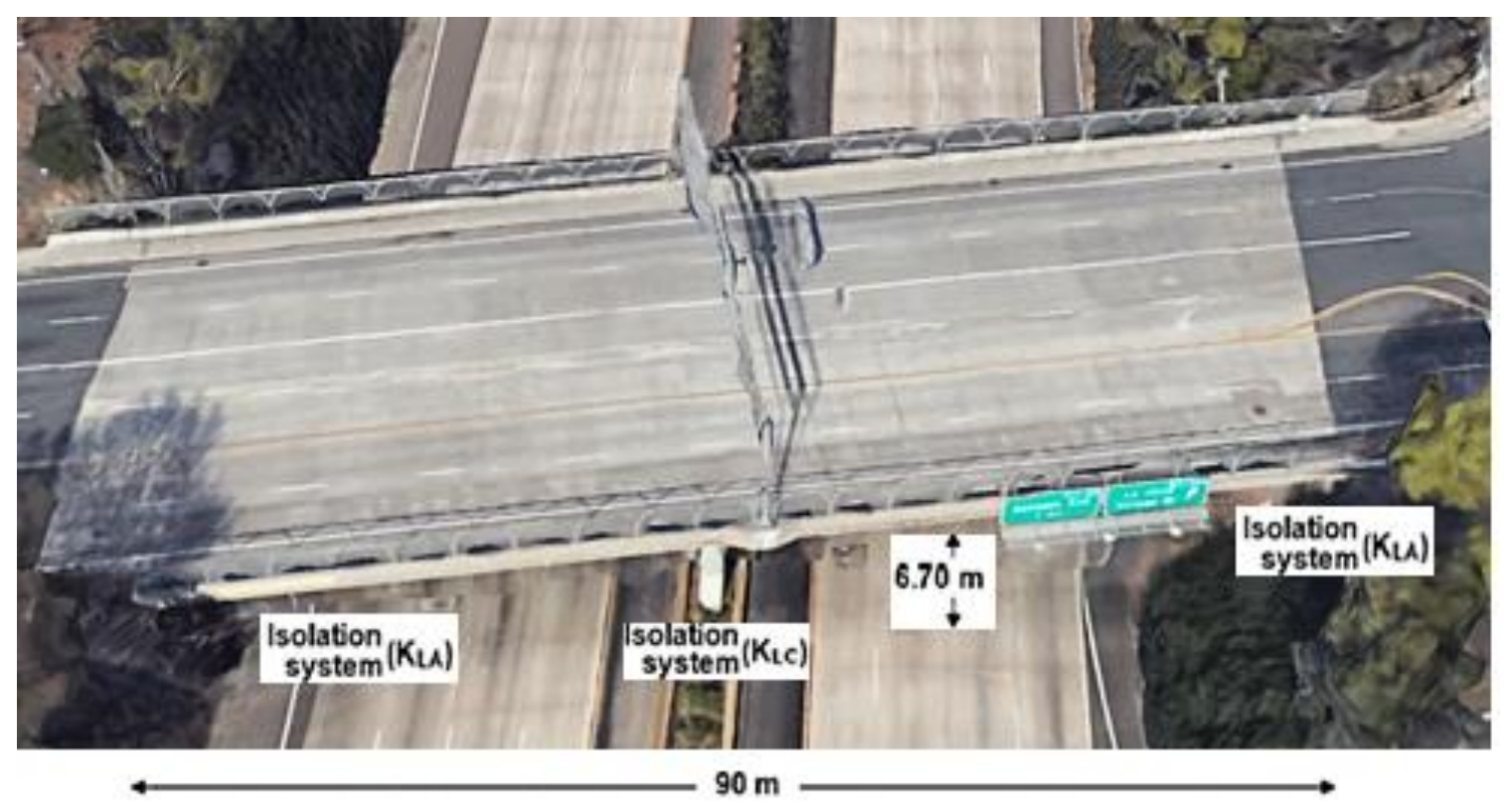

Figure 1. Benchmark Bridge. 

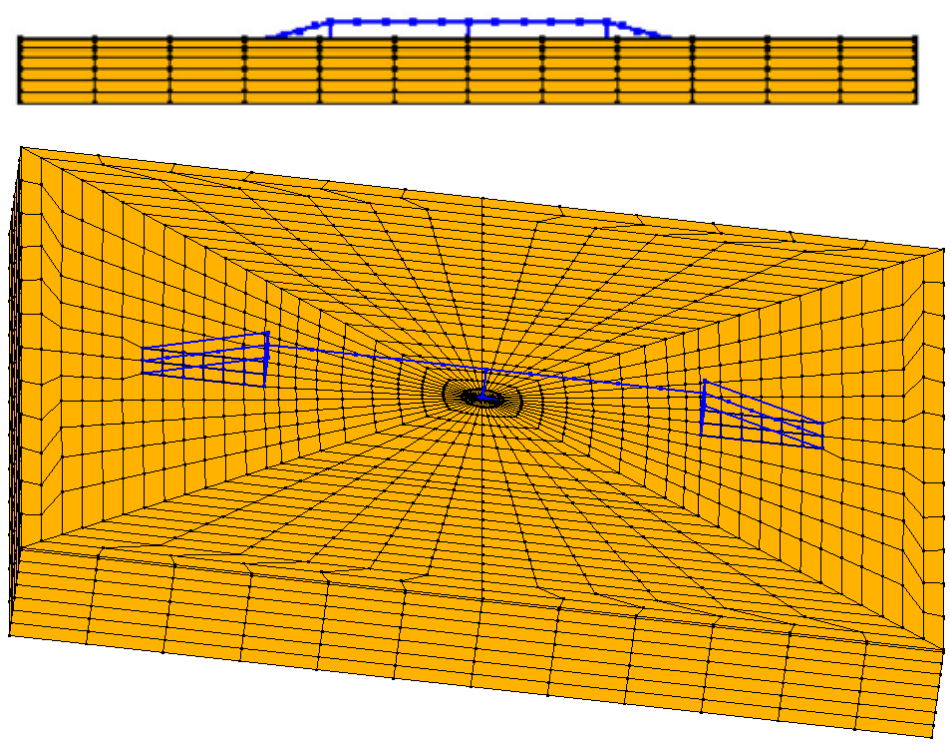

Figure 2. Numerical model.

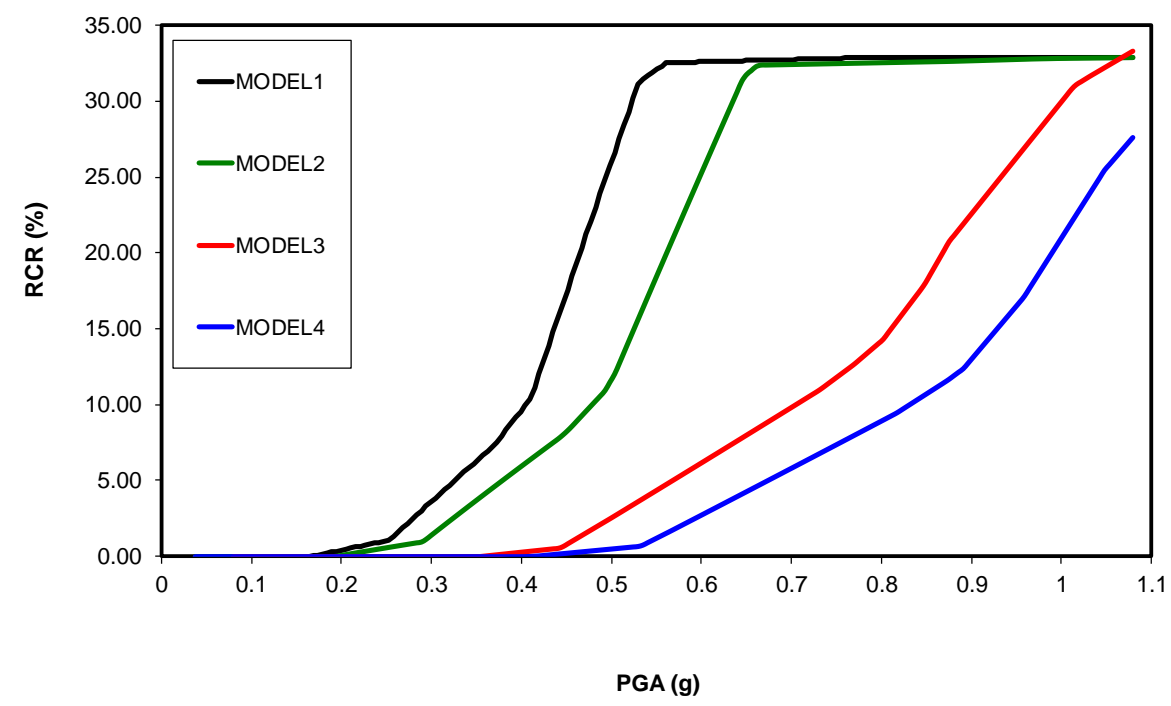

Figure 3. Total repair cost ratio (RCR) calculated by the PBEE methodology.

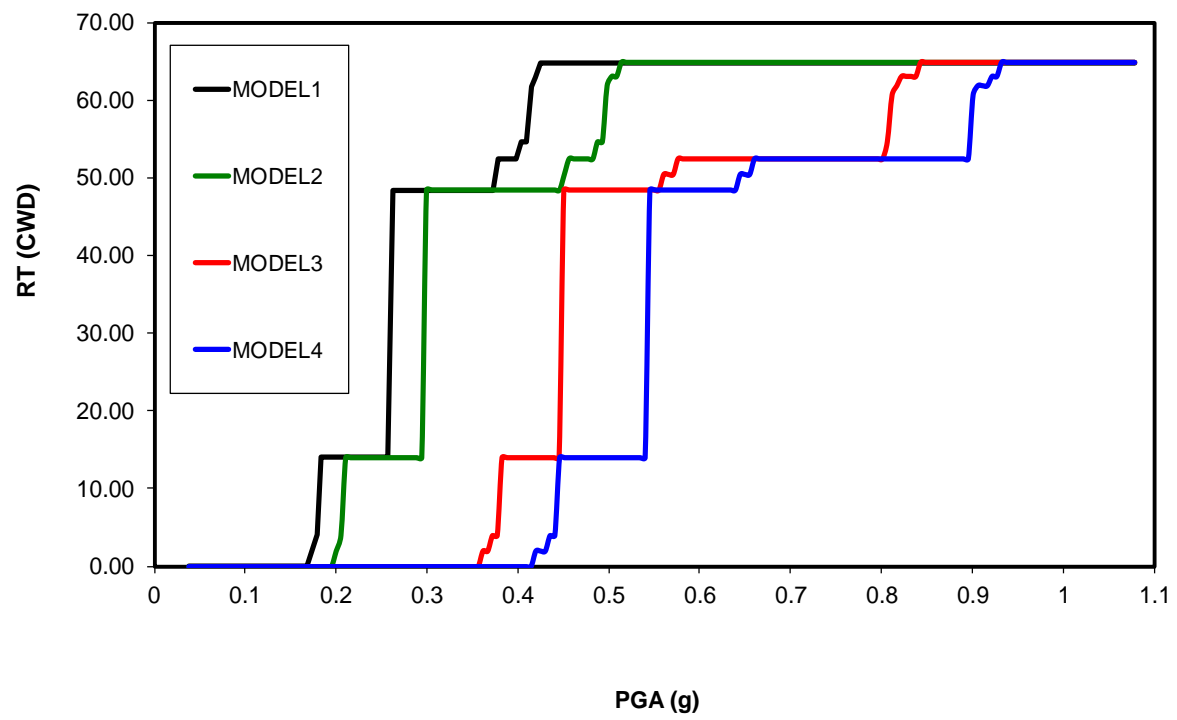

Figure 4. Repair time (RT) calculated by the PBEE methodology. 
Table 1. Characteristics of the various models.

\begin{tabular}{cccc}
\hline Model & KLA $[\mathbf{k N} / \mathbf{m}]$ & KLC $[\mathbf{k N} / \mathbf{m}]$ & ISOLATION \\
\hline Model 1 & 0 & Fixed & No isolation \\
Model 2 & 4000 & Fixed & On abutments \\
Model 3 & 0 & 10000 & On column \\
Model 4 & 4000 & 10000 & Double isolation \\
\hline
\end{tabular}

\section{4- Methodology}

This section shows how that the general methodology can consider several relationships between losses and PBEE quantities. The proposed case study allows to calculate several typologies of losses by considering the hypotheses and assumptions discussed in the previous section. First of all, direct costs are calculated considering the repair cost ratio defined in section 2:

$\mathrm{D}(\mathrm{PGA})=\mathrm{RCR}(\mathrm{PGA})$

Such quantity is expressed in terms of percent respect to the cost of replacement.

Then, two typologies of indirect costs are calculated here. The ones due to the loss of connectivity (named C) and the ones that are due to prolongation of time (and named P).

In particular, $\mathrm{C}$ is calculated as:

$\mathrm{C}(\mathrm{PGA})=\mathrm{c} \times \mathrm{RT}(\mathrm{PGA})$

Parameter c takes into account the effective connectivity of the network which the considered bridge is part of.

Statistical studies on historical events are fundamental to take into account realistic values of such parameter. In this paper three values have been considered of c $(0.10,0.20$ and 0.50$)$, in order to take into account several scenarios of increasing connection schemes. In particular, high value of $\mathrm{c}$ means that the network has low redundancy (the chance of connection loss in not negligible), as shown in [22].

Moreover, $\mathrm{P}$ is calculated as:

$\mathrm{P}(\mathrm{PGA})=\mathrm{p}_{1} \times \mathrm{RT}(\mathrm{PGA})+\mathrm{p}_{2}$

Where the parameters $\mathrm{p} 1$ and $\mathrm{p} 2$ take into account the characteristics of the network in terms of temporal prolongation of travel. Such typology of losses is important when a network is redundant. P should take into account additional travel time, vehicle operating costs and increased risk of accidents. Specific studies on the network are fundamental in order to calibrate these two parameters.

This paper takes into account that when the travel prolongations of time due to long and congested detours are big, the journey can become prohibitive for commercial and industrial traffic. Therefore, when P reaches a particular level (defined by the network characteristics), the entire journey is not covered anymore. In this regard, three scenarios have been considered with increasing the $\mathrm{p} 2$ value $(0.10,0.20$ and 0.50$)$. The parameter $\mathrm{p} 1$ is considered constant and equal to 0.05 , in order to maintain $P$ values smaller than the other sources of losses. Table 2 shows the values considered for each typology of indirect losses. The results on terms of the calculated indirect losses were summed to the direct costs in order to calculate the total costs.

Table 2. Considered scenarios.

\begin{tabular}{cccc}
\hline Scenario & D & C & P \\
\hline Scenario 1 & $100 \%$ & 0.10 & 0.10 \\
Scenario 2 & $100 \%$ & 0.20 & 0.20 \\
Scenario 3 & $100 \%$ & 0.50 & 0.50 \\
\hline
\end{tabular}




\section{5- Results and Discussion}

This section shows the results in terms of indirect costs (loss of connectivity and prolongation costs) and total costs (the sum of direct costs and indirect costs). Figure 5, 6, 7 show the indirect costs connected with loss of connectivity. If these results are compared with the direct costs shown in Figure 3 (named D), they can be significantly low (c=0.10), smaller than D $(c=0.20)$ or similar to $\mathrm{D}(\mathrm{c}=0.50)$. Since $\mathrm{C}$ are proportional to RT, they have similar trends (compare with Figure 4). These curves show significant increase in the losses, when certain limit states are reached.

Figure 8, 9 and 10 show indirect costs connected with prolongation of time (P). These losses are lower if compared with those calculated for loss of connectivity (compare with Figure 5, 6 and 7). As shown in the previous section, this is due to the hypothesis that the journey becomes critical but still non-prohibitive to be overtaken when the bridge is not functional.

Figure 11, 12 and 13 show total costs. When indirect losses (in terms of $\mathrm{C}$ and $\mathrm{P}$ ) are considered, the total costs can become significant big and cannot be neglected. In particular, when scenario 3 is considered, the total costs become $68.8 \%$ (almost 2 times than the maximum value of direct cost shown in Figure 3). In these cases, neglecting indirect losses is detrimental and not acceptable in decision making procedures. In addition, when indirect costs are considered, they can modify significantly the shape of the curves. In particular, there are certain values of PGA (in correspondence with particular limit states) where the increases of total costs are due to the presence of indirect losses (around $+15 \%$ for scenario 3 , around $+10 \%$ for scenario 2 and $+5 \%$ for scenario 1 ).

These findings are fundamental in order to perform resilience-based assessments of bridgeworks subject to multiple hazards. In particular, there could be several novel applications: (a) assessment of multiple hazards, (b) consideration of their interactions and (c) assessment of indirect (as well as direct) losses. In addition, inclusion of indirect losses is particularly important, as to assess the organizational and social aspects (related to the entire community). The framework may be of benefit to public administrators and/or transportation owners who will be able to establish a list of priorities for the protection or repair procedures on bridge different configurations. Importantly, active stakeholder participation with the frameworks will be encouraged beyond the duration of the project and it is expected that this will prompt new concepts and tools for strategic and operational planning purposes. Stakeholders can assess investments on potentially vulnerable bridges depending on the losses in terms of cost and time connected with multiple hazards.

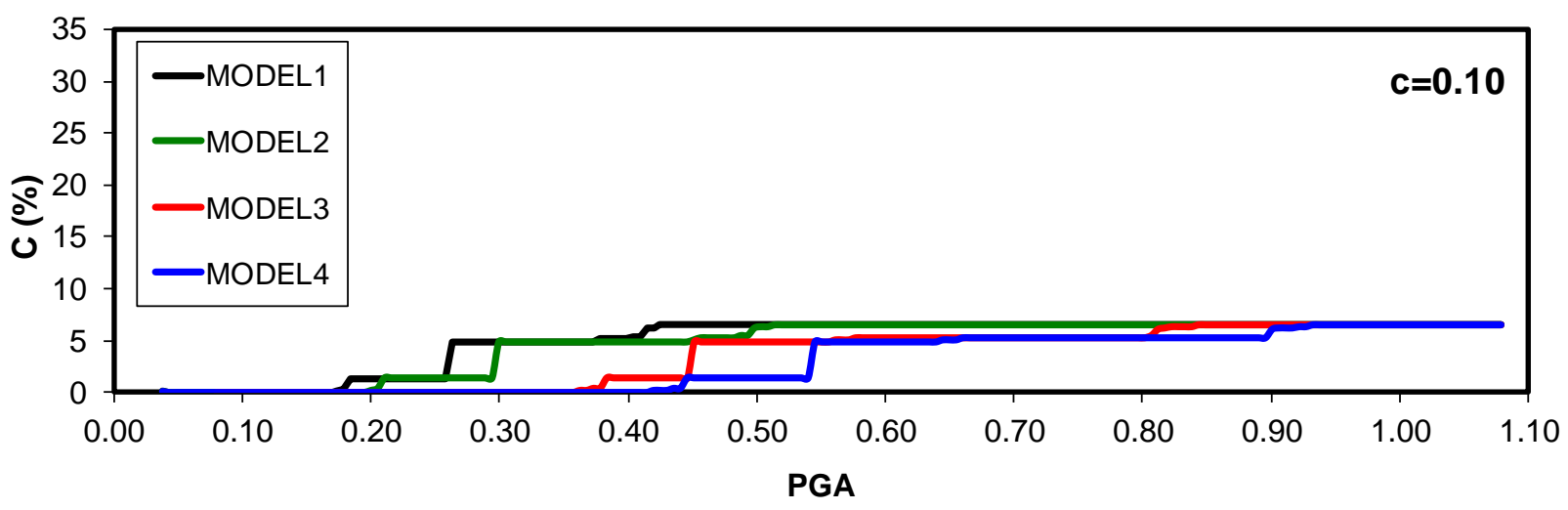

Figure 5. Indirect losses due to connectivity losses (C). Scenario 1: $c=0.10$.

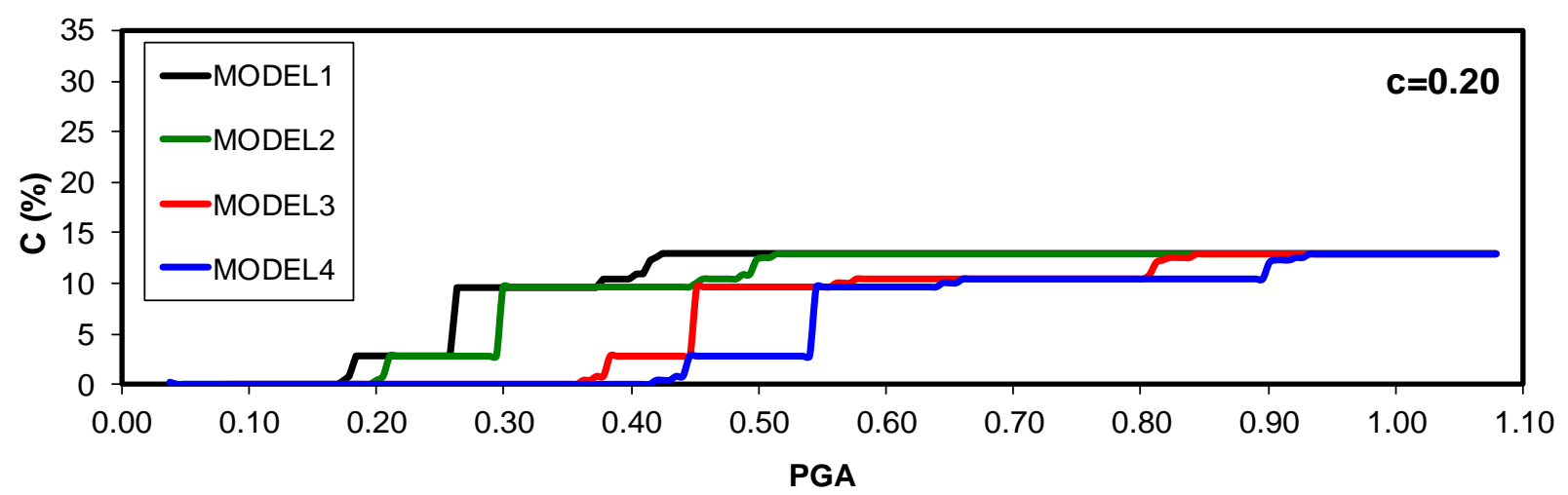

Figure 6. Indirect losses due to connectivity losses (C). Scenario 2: c=0.20. 


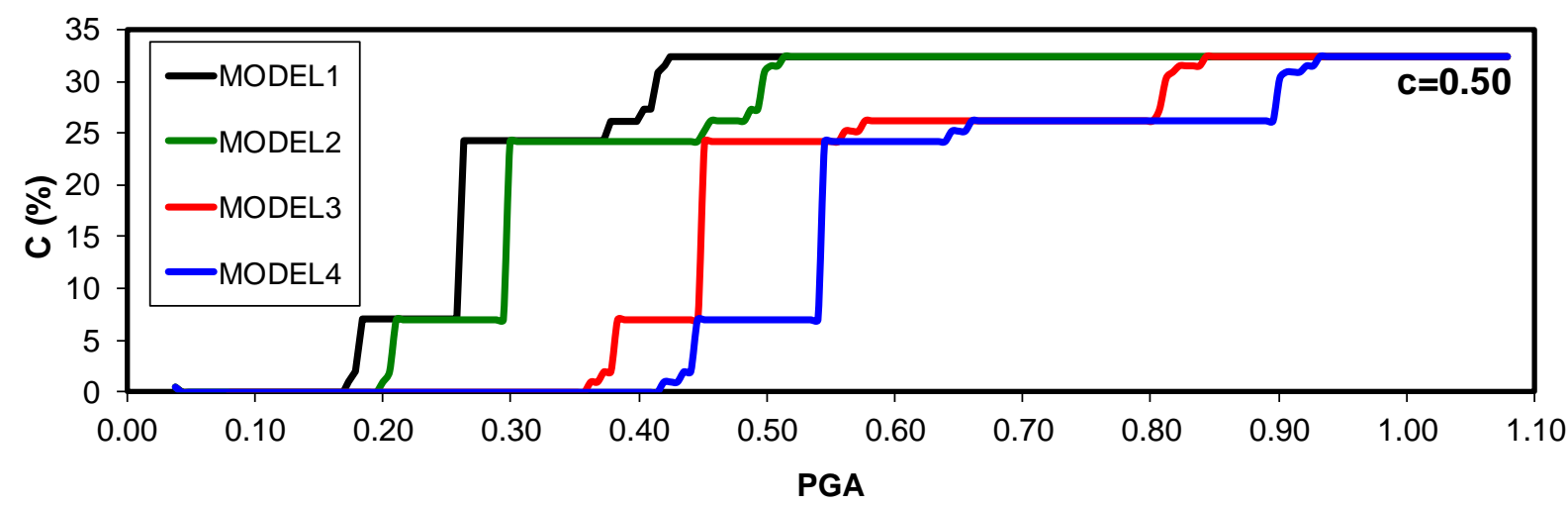

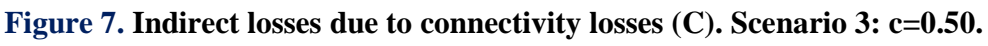

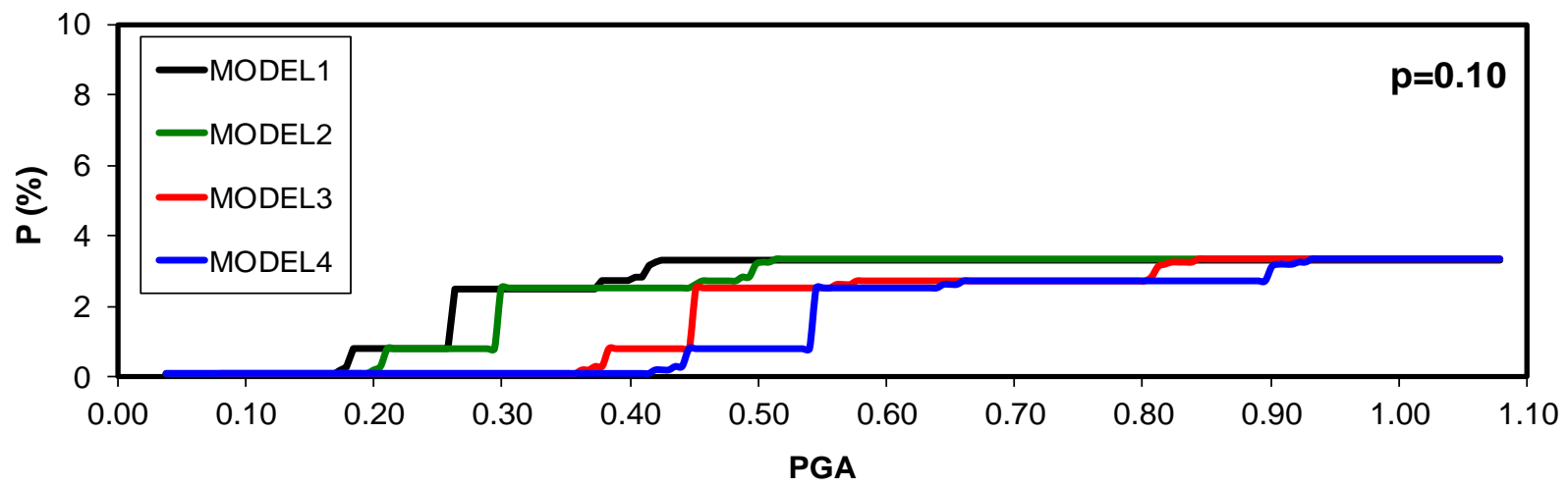

Figure 8. Indirect losses due to prolongation of time (P). Scenario 1: $\mathbf{p}_{2}=\mathbf{0 . 1 0}$.

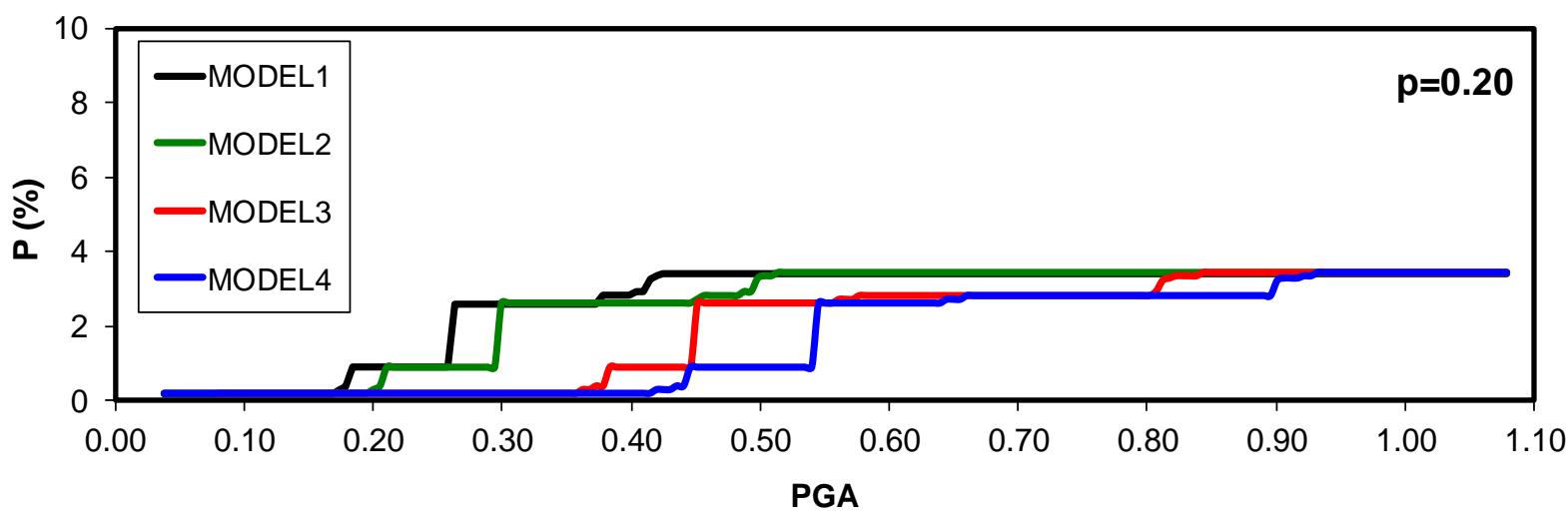

Figure 9. Indirect losses due to prolongation of time (P). Scenario 2: $\mathbf{p}_{2}=\mathbf{0 . 2 0}$.

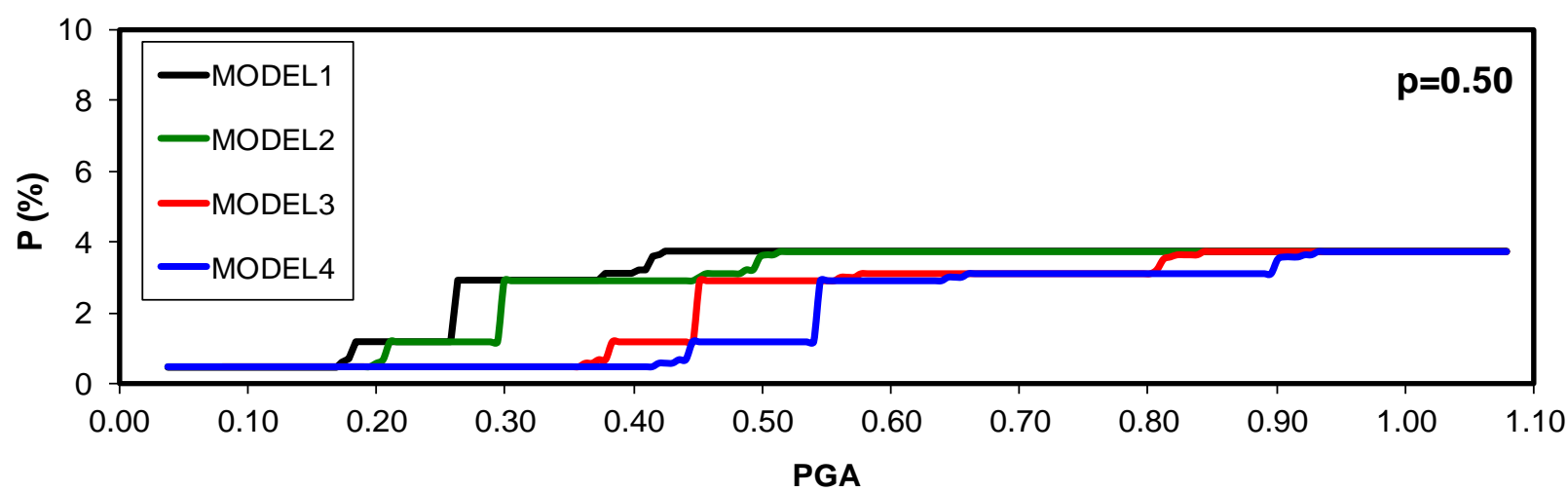

Figure 10. Indirect losses due to prolongation of time (P). Scenario 3: $\mathbf{p}_{2}=\mathbf{0 . 5 0}$. 


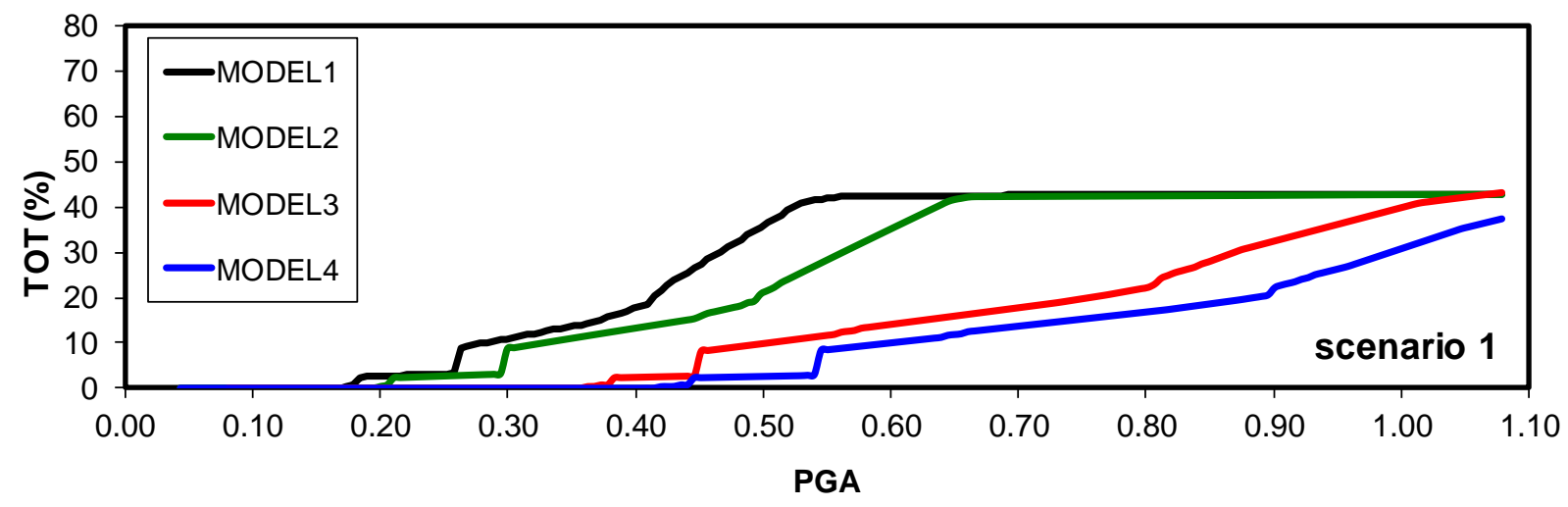

Figure 11. Total losses. Scenario 1.

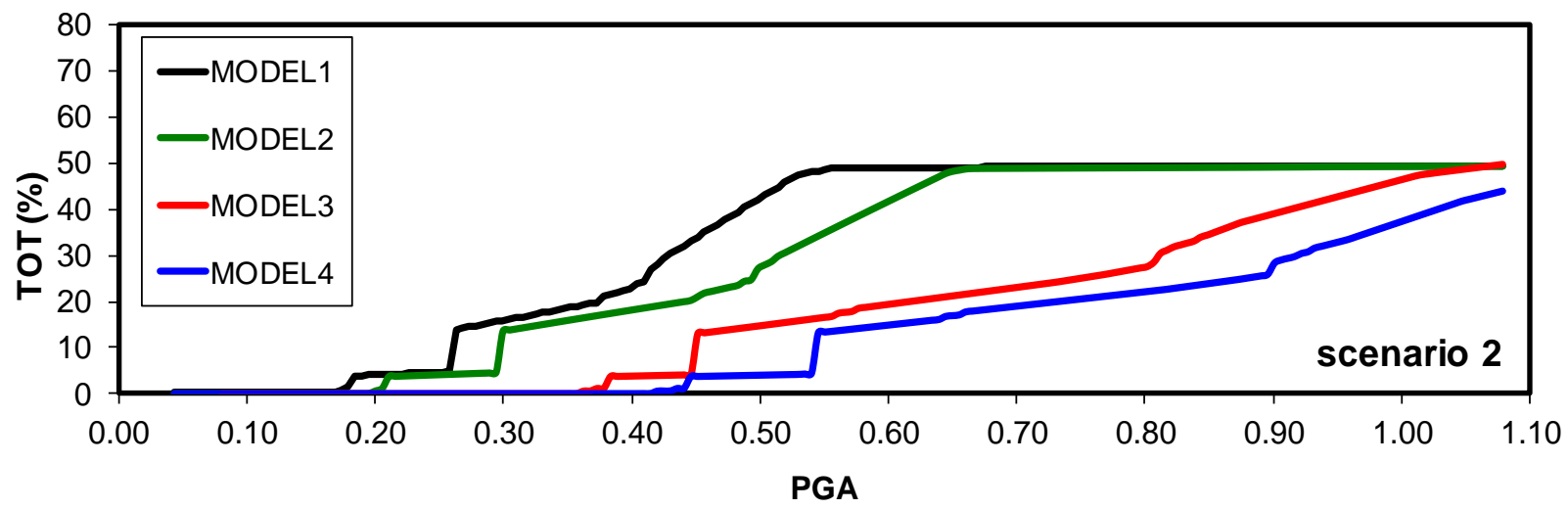

Figure 12. Total losses. Scenario 2.

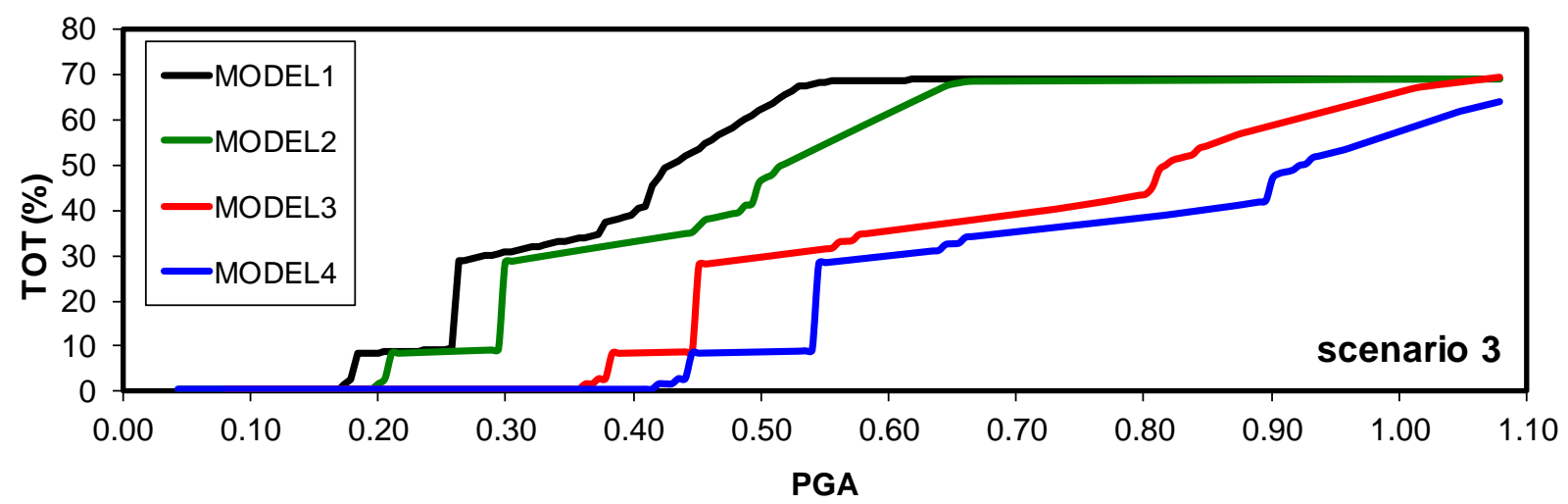

Figure 13. Total losses. Scenario 3.

\section{6-Conclusion}

This paper proposes a methodology that allows to take into account indirect costs in bridge decision making procedures. This approach can be applied in order to study the resilience of bridge during multiple hazards. The paper several formulations of indirect losses that are based on PBEE methodology, from the PEER center. Indirect losses are divided into connectivity losses and prolongation of time. The latter is important when a network is redundant and it should take into account additional travel time, vehicle operating costs and increased risk of accidents. The presented formulation has been applied to a real case study aimed at strengthening a benchmark bridge with several isolated configurations. The proposed methodology allows to evaluate possible solutions to strengthen the original configuration. In particular, several scenarios of increasing connection schemes have been considered. The presented results may be taken into consideration in order to assess structural performances in terms of socio-economic decision variables. The comparison between recovery solutions can be expressed in quantities known to engineers, professionals and stakeholders. The approach can be extended to other typologies of hazards. This will contributes to dispread the proposed methodology as a new easy-to-use decision making approach across the world. Future studies are needed to consider 
other typologies of indirect losses and to extend to other typologies of natural hazards. In this regard, it will be necessary to model realistic relationships that can be obtained with calibration procedures based on statistical approaches.

\section{7- Conflict of Interest}

The authors declare no conflict of interest.

\section{8- References}

[1] Forcellini, D (2017). "Cost Assessment of isolation technique applied to a benchmark bridge with soil structure interaction." Bulletin of earthquake Engineering, doi: 10.1007/s10518-016-9953-0.

[2] Gelh P., D'Ayala D. (2016) "Development of a Bayesian Networks for the multi-hazard fragility assessment of bridge systems", Structural Safety 60. 37-46. doi: 10.1016/j.strusafe.2016.01.006.

[3] Andric J.M and Lu D (2016). "Risk assessment of bridges under multiple hazards in operation period". Safety Science (83): 8092. doi: 10.1016/j.ssci.2015.11.001.

[4] Quang C., Shen J.J Zhou, M., Lee G.C. (2015). "Force-based and displacement-based reliability assessment approaches for highway bridges under multiple hazard actions". Journal of traffic and transportation engineering: 2(4):223-232.

[5] Alipour A., Shafei B., M., Shinozuka M. (2015). "Reliability-based Calibration of Load and Resistance Factors for Design of RC bridges under multiple extreme vents: sour and earthquake.”. Journal of Bridge Engineering, 2013, 18(5): 362-371.

[6] Pitilakis, K., Argyroudis, S., Kakderi, K., Selva J. (2016) Systemic vulnerability and risk assessment of transportatio systems under natural hazards towards more resilient and robust infrastructures. Transportation Research Procedia 14 ( 2016 ) $1335-1344$. doi: 10.1016/j.trpro.2016.05.206.

[7] Wardhana K, Hadipriono F (2003) Analysis of recent bridge failures in the United States. J. Perform. Constr. Facil. 17(3):144150. ISSN: 0887-3828.

[8] Federal Highway Administration (FHWA) (2015) Deficient Bridges by State and Highway System. US Department of Transportation. ASCE (2017) Infrastructure Report Card.

[9] Bruneau, M., Chang, S., Eguchi, R., Lee, G., O’Rourke, T., Reinhorn, A.M., Shinozuka, M., Tierney, K., Wallace, W. and Winterfelt, D. (2003). “A framework to Quantitatively Assess and Enhance the Seismic Resilience of Communities”. E. Spectra, 19(4), 733-7. doi: 10.1193/1.1623497.

[10] Zhang W, Wang N (2016). Resilience-based risk mitigation for road networks. Structural Safety, 62: 57-65. doi: 10.1016/j.strusafe.2016.06.003.

[11] Cimellaro G. (2016) "Urban resilience for emerging response and recovery", Springer, DOI: 10.1007/978-3-319-30656-8. doi: 10.1061/(ASCE)ST.1943-541X.0001672.

[12] Gidaris I., Padgett J.E., Barbosa A.R., Chen S. (2017) "Multiple-Hazard Fragility and Restoration Models of Highway Bridges for Regional Risk and Resilience Assessment in the United States: State-of-the-Art Review”, Journal of Structural Engineering, 143(3): 04016188. doi: 10.1061/(ASCE)ST.1943-541X.0001672.

[13] Tierney K.J. (1995) "Impacts of recent US disasters on businesses: the 1993 midwest floods and the 1994 Northridge Earthquake", Preliminary paper n.270, University of Delaware Disaster Research Center.

[14] Wasileski, G., Rodríguez, H., Diaz, W. (2011) "Business closure and relocation: a comparative analysis of the Loma Prieta earthquake and Hurricane Andrew” Disasters, 35 (1), pp. 102-129. doi: 10.1111/j.1467-7717.2010.01195.x.

[15] Webb, G.R., Tierney, K.J., Dahlhamer, J.M. (2002) "Predicting long-term business recovery from disaster: A comparison of the Loma Prieta earthquake and Hurricane Andrew" Global Environmental Change Part B: Environmental Hazards, 4 (2), pp. 4558. doi: 10.3763/ehaz.2002.0405.

[16] Chang, S.E., Svekla, W.D. , Shinozuka M. (2002) "Linking infrastructure and urban economy: simulation of water-disruption impacts in earthquakes" Environment and Planning B, 29 (2), pp. 281-302.

[17] Miles S.B. and Chang S.E. (2003) “Urban Disaster Recovery: A Framework and Simulation Model”MCEER-07-0014(PB2004104388,CD-A07). ISSN 1520-295X

[18] Chang, S.E. and Shinozuka,M. (2004) "Measuring Improvements in the Disaster Resilience of Communities." Engineering Structures 20(2), 739-755.

[19] Renschler, C., Frazier, A., Arendt, L., Cimellaro, G.P., Reinhorn, A.M., Bruneau M. (2010) "Framework for Defining and Measuring Resilience at the Community Scale: The PEOPLES Resilience Framework” T. Report MCEER-10-006 (2010), Univ at Buffalo, NY. doi: 10.1007/978-94-017-8875-5_27. 
[20] Brookshire DS, Chang SE, Cochrane H, Olson RA, Rose A, Steenson, J (1997) "Direct and Indirect Economic Losses from Earthquake Damage". Earthquake Spectra; 14 (4): 683-701.

[21] Forcellini, D. (2016) “A Direct-Indirect Cost Decision Making Assessment Methodology for Seismic Isolation on Bridges”, J. of Mathematics and System Science, vol. 4, No. 03-04, 85-95. doi: 10.17265/2328-224X/2015.0304.002.

[22] Adey B, Hajdin R, Brudwile E (2004) "Effect of common cause failures on indirect costs". Journal of Bridge Engineering 9 (2): 200-208.

[23] Lu, J., Mackie, K.R., and Elgamal, A. (2011) "BridgePBEE: OpenSees 3D Pushover and Earthquake Analysis of Single-Column 2-span Bridges, User Manual, Beta 1.0”, http://peer.berkeley.edu/bridgepbee/.

[24] Mackie K.R., Lu J, Elgamal A (2010) "User interface for performance-based earthquake engineering: a single bent bridge pilot investigation". 9th US National and 10 th Canadian Conference on Earthquake Engineering: Reaching Beyond Borders, Toronto, Canada.

[25] Billah AHM, Alam MS (2015). Seismic fragility assessment of highway bridges: a state-of-the-art review. Str \& Infrastr Eng 11(6):804-832. doi: 10.1080/15732479.2014.912243.

[26] Karamlou A. and Bocchini P. (2015) "Computation of bridge seismic fragility by large-scale simulation for probabilistic resilience analysis”. Earthquake Engng Struct. Dyn. 2015; 44:1959-1978. doi: 10.1002/eqe.2567.

[27] Kelly JM (1997) Earthquake-Resistant Design with Rubber, 2nd ed., Springer-Verlag, London, UK. doi: 10.1007/978-1-44710971-6

[28] Forcellini D, Kelly JM (2014) The analysis of the large deformation stability of elastomeric bearings. Journal of Engineering Mechanics, ASCE; 140(6):04014036. doi: 10.1061/(ASCE)EM.1943-7889.0000729. 